\title{
PELATIHAN PENULISAN JURNAL ILMIAH DI SEKOLAH TINGGI ILMU-ILMU SOSIAL (STIS) TUAL
}

\author{
Erwin Ubwarin ${ }^{1}$, Jacob Hattu ${ }^{2}$, Elias Zadrak ${ }^{3}$, Leasa Patrick Corputty ${ }^{4}$, \\ Wilshen Leatemia ${ }^{5}$ \\ 1,2,3,4,5) Program Studi Ilmu Hukum, Fakultas Hukum, Universitas Pattimura \\ e-mail: eubwarin@gmail.com
}

\begin{abstract}
Abstrak
Pengabdian masyarakat bukan saja dilakukan pada masyarakat pada umumnya, namun juga bisa untuk masyarakat kampus, yang salah satunya adalah dosen. Dosen merupakan ujung tombak perubahan, sehingga kualitas dosen dapat diukur dari penelitian dan pengabdian yang dipublikasikan pada jurnal, pengabdian ini dilakukan pada Sekolah Tinggi Ilmu-Ilmu Sosial (STIS) Tual. Metode pengabdian mengunakan sosialisasi dan model pembelajaran jigsaw Hasilnya pengabdian ini mereka jadi mengetahui pentingnya publikasi jurnal dan tumbuh budaya menulis, pelatihan dilakuan enam tahap yang tiap tahap akan diukur perubahannya, tahap pertama menjadi kunci karena hasil tes akan kami campur yang sudah mampu publikasi karya ilmiah dan yang belum bisa, jika belum ada perhubahan bagi temang yang belum mampu maka teman yang sudah mampu publikasi akan membantu teman yang belum bisa memahami materi yang disampaikan, hal inilah mengapa sampai memakai metode jigsaw agar penyerapan materi dapat dilakukan dengan baik. Kurang mampu dosen mempublikasikan karya penelitian dan pengabdian, akan merugikan masyarakat umumnya dan dosen sendiri pada khususnya, hasil karya ilmiah ini dapat diakses gratis oleh semua orang.
\end{abstract}

Kata kunci: Pelatihan, Penulisan, Jurnal

\begin{abstract}
Community service is not only carried out for the community in general, but also for the campus community, one of which is a lecturer. The dose is the tip for change, it can be measured from research and the quality of service to journals, this service is carried out at the Tual College of Social Sciences (STIS). The service method utilizes socialization and the jigsaw learning model. As a result of this service, they become aware of the importance of journal publication and the growth of writing culture. The training is carried out in six stages, each stage will measure the changes, the first stage is the key because we will mix test results that are already capable of publishing scientific papers and those who cannot, if there is no change for friends who are not able to, then friends who are able to publish will help friends who cannot understand the material presented, this is why they use the jigsaw method so that the absorption of material can be done well. Lack of ability for lecturers to publish research and service works will harm the general public and the lecturers themselves in particular, the results of this scientific work can be accessed free of charge by everyone.
\end{abstract}

Keywords: Training, Writing, Journal

\section{PENDAHULUAN}

Di era perkembangan teknologi 4.0, membuat manusia tidak lagi terbatas akan ruang dan waktu, hasil penelitian kita di Indonesia bisa diakses di seluruh dunia, gratis sehingga orang dapat mengenal kita. Pada pengabdian ini kami tim Jurnal Belo Fakultas Hukum Universitas Pattimura, diberikan undangan dari Sekolah Tinggi Ilmu-Ilmu Sosial (STIS) Tual untuk membantu mereka untuk mengenjot publikasi Ilmiah yang dimiliki. STIS Tual merupakan salah satu Perguruan Terkemuka di Kota Tual Maluku (Sarkol, T.,Ayomi,P. K.,Ubwarin, E., 2021) Sebelum melakukan pengabdian kami melakukan beberapa pengambilan data awal dengan membagikan kuesioner untuk mengetahui bagaimana kempuan para dosen disana mengenal teknik menulis sesuai gaya selingkung jurnal, metode penelitian, cara menghasilkan suatu karya ilmiah yang berkualitas, data tabulasi kami menunjukan bahwa hanya $12 \%$ yang mempunyai karya Jurnal Ilmiah, namun ada juga sisi potensi yang mereka punyai yaitu mereka $100 \%$ mempunyai karya ilmiah lain selain jurnal, tentunya karena dosen mereka pastinya telah mengerjakan skripsi dan tesis pada Pendidikan Strata Satu dan Starata Dua. 
Sumber Daya Manusia di Sekolah Tinggi Ilmu-Ilmu Sosial (STIS) Tual, memang sedikit berbeda dengan data pelaporan yang dimasukan ke https://pddikti.kemdikbud.go.id/ karena ada penambahana beberapa penambahan Dosen Baru yang mempunyai kualitas baik dalam melakukan publikasi. Data https://sinta.ristekbrin.go.id/ Sekolah Tinggi Ilmu-Ilmu Sosial (STIS) Tual berada pada peringkat 2855 dengan 7 Karya Ilmia yang terekap didalam sistem Sinta, tentunya ini adalah kendala tersendiri dalam melakukan perbaikan. Jadi kegiatan ini bertujuan untuk melakukan peningkatan terhadap karya publikasi jurnal ilmiah dari Sekolah Tinggi Ilmu-Ilmu Sosial (STIS) Tual.

\section{METODE}

Metode yang dipergunakan pada pelatihan jurnal dilakukan dengan adalah memberikan penyuluhan yang bertujuan meningkatkan pemahaman peserta namun memakai metode Jigsaw, (Ubwarin, E., Gaspesz, N., \& Sisinaru, S,. Y. 2019), kenapa memakai metode Jigsaw karena metode ini didesain untuk meningkatkan rasa tanggung jawab peserta terhadap pembelajarannya sendiri dan pembelajaran orang lain. Peserta tidak hanya mempelajari materi yang diberikan, tetapi mereka harus siap memberikan dan mengajarkan materi tersebut pada anggota kelompok yang lain. Dengan demikian, siswa saling tergantung satu dengan yang lain dan harus bekerja sama secara kooperatif untuk mempelajari, Amargawati (Ambar Dwi. 2017).

\section{HASIL DAN PEMBAHASAN}

Pelatihan pada STIS Tual dimulai dengan beberapa tahapan, dan dilakukan evaluasi pada ahir kegiatan agar mengetahui kemampuan dayaserap perserta kegiatan :

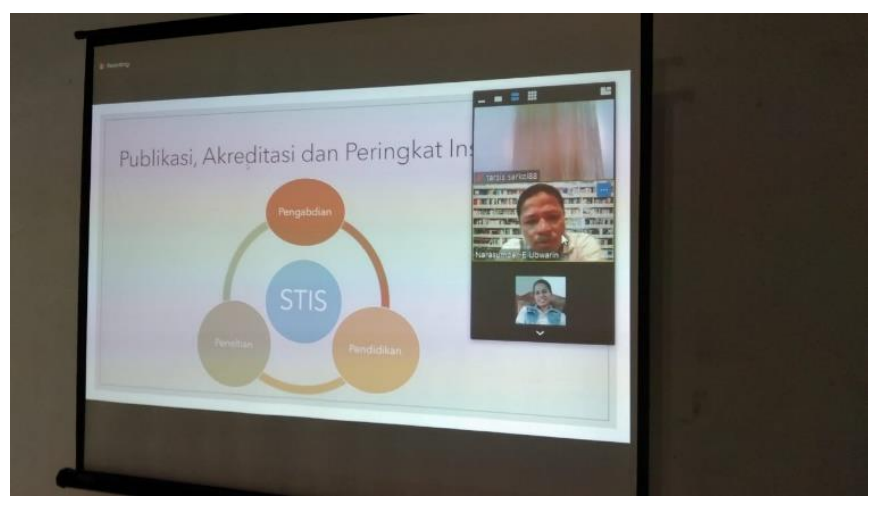

Gambar I. Pemberian Materi Melalui Aplikasi zoom cloud meeting

a. Tahap I

Pada tahap I, saya dan tim membagikan kuesioner melalui google form, untuk mengetahui bagaimana tingkat pemahaman perserta tetang publikasi karya ilmu yaitu jurnal pada lingkup STIS Tual. Hasil diketahui bahwa:

1) $73 \%$ Dosen belum mengetahui publikasi ilmah secara baik, $17 \%$ sudah mengetahui, $10 \%$ belum mengenal sama sekali publikasi karya ilmiah

2) $90 \%$ Sudah perna mempublikasikan jurnal baik yang cetak maupun yang daring, $10 \%$ belum perna mempublikasikan karya ilmiah dalam bentuk jurnal.

3) $83 \%$ Dosen belum mempublikasikan jurnal secara daring, dan $17 \%$ sudah perna mempublikasikan jurnal secara daring baik itu Jurnal luaran penelitian maupun pengabdian kepada masyarakat.

b. Tahap II

Dari data tahap I, kami mencoba mengengelompokan berdasarkan program studi, kemampuan publikasi karya ilmiah dan jabatan fungsional, dibagi secara merata sehingga diharapkan dengan metode Jigsaw ini akan terjadi penularan pengetahuan bagi yang belum memgetahui dengan benar dan sama sekali belum mengetahui penulisan karya ilmiah itu seperti apa.

c. Tahap III 
Pada tahap III ini kami mulai untuk masuk kedalam kegiatan yang sesunguhnya dengan mulai memberikan materi tentang teknik penulisan, persiapan membuat daftar Pustaka atau mencari sumber refernsi, karea di Tual akses memperoleh Buku agak sulit didapatkan literaur buku yang bisa mereka gunakan sebagi literatur, untuk itu kami memberikan beberapa contoh akses literatur yang gratis, seperti google scholar, https://www.sciencedirect.com/, http://libgen.gs/, yang memberikan data gratis dan bisa dipergunakan untuk menulis jurnal yang berkualitas baik.

d. Tahap IV

Pada tahapan ini kelompok yang sudah dibagi akan mulai bekerja untuk Menyusun rancangan naskah artikel yang mereka buat, sambil menunggu mereka mempersiapkan, kami memberikan contoh jurnal yang kami tulis, bagaimana kita mencari novelty dan state of the art penelitian atau pengabdian masyarakat melalui jurnal.

e. Tahap V

Pada tahapan ini adalah tahap finishing, tahapan ini kami memeriksa kembali jurnal yang ditunju apakah sudah sesuai dengan template, jika sudah sesuai maka tahapan berikut adalah melakukan similarity check tahapan ini kami memeriksa kembali karya ilmiah yang akan dikirim sebagai bentuk pencegahan jangan sampai ada perna tulisan yang sama atau sudah ada yang menulis isu/atau permasalahan yang sama, aplikasi yang kami pakai adalah trunitin, berdasarkan hasil pengecekan ini kami mempebaiki tulisan yang telah ada.

f. Tahap VI

Pada tahapan akhir ini, artikel yang telah diperbaiki kemudian di kirim pada jurnal tujuan yang sudah terindex sinta, kami mengharapkan jika sudah pahan dengan jurnal yang terindex sinta barulah mereka ke jurnal yang terindex scopus dan web of science.

\section{SIMPULAN}

Dosen melakukan pengajaran, penelitian, dan pengabdian, merupakan bentuk dari pengamalan Tri Dharma Perguruan Tinggi, STIS Tual belum maksimal dalam mempublikasikan penelitian dan pengabdian melalui Jurnal Ilmiah, dengan pelatihan ini diharapkan publikasi penelitian dan pengabdian semakin baik, dan muncul budaya menulis hasil penelitian dan pengabdian.

\section{UCAPAN TERIMA KASIH}

Ucapan terima kasih kami sampaikan kepada Dekan Fakultas Hukum Universitas Pattimura yang telah memberikan kami bertiga surat tugas untuk melakukan pengabdian pada STIS Tual dan para tenaga pendidik STIS Tual yang telah mempersilakan kami melakukan pengabdian kepada masyarakat.

\section{DAFTAR PUSTAKA}

Salamor, A. M., Salamor, Y. B., Ubwarin, E., (2020), Trauma Healing Dan Edukasi Perlindungan Anak Pasca Gempa Bagi Anak-Anak Di Desa Waai, Community Development Journal: Jurnal Pengabdian Masyarakat 1 (3). https://doi.org/10.31004/cdj.v1i3.1015

Sarkol, T., Ayomi, P. K., Ubwarin, E., (2021) Penyuluhan Hukum Bebas Korupsi dan Tertib Administrasi Kepada Pemerintah Ohoi Ohoiren, AIWADTHU: Jurnal Pengabdian Hukum 1 (1).

Ubwarin, E., Leasa, E. Z., Saimima, J.M., Leatemia, W., (2020), Pelatihan Paralegal Gereja Protestan Maluku Klasis Seram Barat, Community Development Journal: Jurnal Pengabdian Masyarakat 1 (3), https://doi.org/10.31004/cdj.v1i3.1040

Ubwarin, E., Hattu, J., (2020) Leatemia, W., Budaya Hukum Anti Korupsi Pada Warga Binaan Lapas Klas II A Ambon. Community Development Journal: Jurnal Pengabdian Masyarakat 1 (2). https://doi.org/10.31004/cdj.v1i2.706

Ubwarin, E., Gaspesz, N., \& Sisinaru, S,. Y. (2019). Community Empowerment through The Hygiene and Competitive Production of Balobo Salted Fish, MITRA: Jurnal Pemberdayaan Masyarakat, 3 (2), 141-150 